\title{
Disciplining the Transgendered: Brandon Teena, Public Representation, and Normativity
}

\author{
John M. Sloop
}

\begin{abstract}
"How can we have a discussion of how much sex and gender divergity actually exists in society, when all the mechanisms of legal and extralegal repression render our lives irsvisible?" (Feinberg 102).
\end{abstract}

"Re-envisioning rhetoric as a constructor of gender rather than as constructed by gender is an essential step toward. . . liberation" (Condit 110 ).

T HE CORE OF THE STORY of Brandon Teena is fascinating enough, and emotional enough, that most people remember its outline with very little prompting. This story was retold repeatedly and widely, in local nowspapers, as well as in The Village Voice and Playboy. Lt has been the subject of a true crime book, multiple web sites, a play, a documentary film (The Brandon Teena Story), a feature flm (Boys Don't Cry), and the first on-line Guggenheim art project. ${ }^{1}$ The bare bones of the story, as recounted through mass mediated outlets, go something like this: Brandon Teena (born Teena Brandon) ${ }^{2}$ was a 21 year old woman who moved from Lincoln, Nebraska, where she had been "living as a man," to the smaller town of Falls City, Nebraska in late 1993. While Brandon's move was prompted by a number of brushes with the law based on his tendency to forge checks and use credit cards without permisgion, it was also a move that allowed Brandon a fresh start with a male identity in a community where he had no history as a woman. In little time, Brandon found a circle of friends and, as he had done in Lincoln, began dating several of the women in that circle, with many of them reporting later that Brandon was the "ideal man." His financial problems continved, however, and Brandon was once again arrested for check cashing fraud. During a court appearance on that charge, Brandon was served with another warrant for a check fraud case in Eincoln. This time,

JOHN M. SLOOP (PhD, University of Iowa) is Assistant Professor in the Department of Communication Studies and Theatre at Vanderbilt University. The author would like to thank David Fenry, the anonymous reviewers, Carole Blair, Bonnie Dow, and, most notably, Sarah Projansky. This essay is dedicated to Brandon Teena. Versions of this essay were presented at the Second Biennial Feminism(s) and Rhetoric(s) Conference in Minneapolis (Oct 1999) and at the Southern States Communication Association Conference in New Orleans (April 2000). 
though, the warrant was issued using Brandon Teena's birth (female) name, and he was jailed as a female. It was with this arrest that the Falls City community, including Brandon's friends, became aware that Brandon was "really" a woman.

Confusion about Brandon's gender in Falls City continued, however, if only because there were so many stories circulating about what Brandon "really was," in part because of Brandon's own use of multiple narratives and in part because so many women claimed intimate knowledge of his "maleness." Perhaps, some argued, Brandon was a hermaphrodite, perhaps he had an accident as a child, or perhaps he was at some stage in the process of a female to male transition. Whatever the case, given Brandon's success with the local women, his "true" gender was a matter of great concern to his friends, especially the men. Regardless of what theory people held about Brandon, his presence provided a clear case of gender trouble in the local community, although none of those involved had much interest in celebrating gender or sexual fluidity.

Events took a much uglier turn while Brandon was attending a party on Christmas Eve. While most of those at the party celebrated the holidays, two of Brandon's male friends-Tom Nissen and John Lotterdecided to clear up any ambiguity by forcing Brandon to reveal his genitals. Discovering that Brandon had a vagina, clearly marking him as a woman in Nissen and Lotter's eyes, the two forced Brandon to leave the party with them and proceeded to drive to a desolate area of town where each in turn raped him. Nissen and Lotter then retumed to the party with Brandon, threatening to kill him if he reported the rapes. While acting as if he was washing up in the bathroom, Brandon locked the door and escaped through a window, making his way to the local police department to report the crime. A week later, with the rape "under investigation" by local authorities (who were skeptical of Brandon), Nissen and Lotter drove to the farmhouse where Brandon was staying with friends, and fatally shot him and two others living in the house. Nissen and Lotter were quickly arrested and, after a media saturated trial, Lotter was given a death sentence and Nissen life imprisonment (in exchange for testifying against Lotter).

The trial was covered widely in the local and national press both because of its unusual nature and because a large number of transgender activists made appearances in and outside of the courthouse. As a result, the story of Brandon Teena's life and death provides a large body of discourse that reflects public discussions of sex, gender, sexuality, and transgenderism. ${ }^{4}$ It is a story that begs cultural refection on gender, sexuality and the possibilities of public performance. Given the topic and the rather large body of discourse the case produced, it is an ideal case through which one can investigate, as Lauren Berlant would suggest, one area of ideological tension over identities within the American landscape $(1,4)$.

Historically, cases of gender ambiguity brought on by public disclosure of transgenderism or hermaphroditism have marked ongoing 
transitions in the meaning of gender within a given cultural context (see, e.g., Garber 11, Holden, Dreger 6). Indeed, Alice Dreger notes that the entire "history of hermaphroditism is rargely the history of struggles over the realities' of sex-the nature of 'true' sex, the proper roles of the sexes, the question of what sex can, should, or must mean" (15). While the Brandon Teena case is not about hermaphroditism" (although hermaphroditism does get invoked), the quantity of discourse that surrounds the case can be read as a site through which we can see public understandings of the "true" meaning of sex, a location at which we might leam something about the struggle over gender as it takes place in a contemporary, and mass mediated, cultural context. Before I provide a reading of the discourse surrounding this case and illustrate the case's articulation through a particular gender/sex ideology, I will lay out my assumptions regarding gender, rhetoric, and cultural/ critical politics.

\section{Performativity, Gender Diversity and Critical Rhetoric}

As has become commonplace in many contemporary discussions of gender and sexuality, at least since the publication of Judith Butler's Gender Trouble, gender and sexuality are assumed in this essay to be potentially fivid, held into check by each individual's interpellation into a cultural ideology that maintains male-female differences. That is, gender is taken here to be performative, at least within the "the forced reiteration of norms" (Gevder 94-5). While Butler's work focuses on both the ways in which gender normativity is tightly bound by cultural logics and the ways that subversion of these logics may take place, a great deal of critical work that takes a performative position on gender has focused on cases of gender transgression (e.g., tranggenderism, drag) to understand how gender might be destabilized. Marjorie Garber, for example, sees transsexualism as a confirmation of the constructedness of gender, and as a result, as tied to the deconstruction of the male-female sexual binarism and of heterosexual normativity (110), and, in a recent special issue of $G L Q$ devoted to transgenderism, editor Susan Stryker notes that "transgender phenomena emerge from and bear witness to the epistemological rif between gender signifiers and their signifieds" (147). In noting that transgenderism can be aligned with queer polities, Stryker acknowledges that transgendered bodies and logics can work to deconstruct those binaries (149). ${ }^{6}$ Further, in the introduction to their early "90s volume, Julia Epstein and Kristina Straub note that ambiguous gender identities "offer a point at which social pressure might be applied to effect a reevaluation of binary thinking" (4). In such works we are rightly pointed to the ways transgendered phenomena and queered ideologies could potentially work to loosen, to make fluid, gender binaries and heteronormativity.

While this move to celebrate or highlight potential disruptions of the gender binary system is indeed a vital project, it can come at the cost of focusing on ways that the dominant rhetoric/discourse of gender contin- 
ues to ideologically constrain. As a rhetorical and cultural critic interested in the politics of doxa, I am more interested in the disciplinary side of the coin - the ways in which, using the words of Ronald Greene, public arguments are based on logics of articulation that work materially to make possible "the ability to judge and plan reality" $(15) .^{7}$ Hence, while cases of gender ambiguity obviously have the potential to cause "gender trouble" and disrupt bigender normativity, in terms of the "dominant" discussions that surround such cases, critics would also be well served by thinking through the ways that the "loosening of gender binarisms" is a potential that often goes unrealized for many audiences. ${ }^{8}$ Hence, even if we hold Butler's position that gender is performative, that sex is always already gendered, we must still pay careful attention to the fact that, in public discourse (doxx), a major assumption still stands that individuals are at base, "sexed." Public discourses concerning cases such as the Brandon Teena narrative-indeed, the reactions of the young men responsible for Brandon's death-are due in part to the fact that so many institutions and individuals work to stabilize sex, to reiterate sexual norms, rather than to encourage/ explore gender fluidity.

As a result, in Butler's words, the discourse surrounding the Brandon Teena story should be read as a public iteration of sexual norms as, "a ritualized production, a ritual reiterated under and through constraint, under and through the force of prohibition and taboo, with the threat of ostracism and even death controlling and compelling the shape of the production" of gender and sexuality (Bodies 95). Hence, while not to deny the potential of the case to "loosen" cultural rules concerning gender, sex, and sexuality, I am approaching the Brandon Teena case as a site of the public stabilization of what Sabrina Ramet refers to as gender culture: "A society's understanding of what is possible, proper, and perverse in gender-linked behavior, and more specifically, that set of values, mores, and assumptions which establishes which behaviors are to be seen as gender-linked" (2). In this study, I am building a "critical rhetoric" narrative, a "gathering of fragments," concerning a case where gender trouble seemingly begs to lead to a transgression of gender barriers and heteronormativity. ${ }^{9}$ While pointing out how gender is renormalized and reessentialized, I am borrowing the assumptions of the critical project of gender diversity outlined by Celeste Condit, a project that critiques gender dichotomy feminism for failing to see how gender is produced through discourse and for failing to see gender and identity as mobile ("In Praise" 91). Utimately, aligned with the performative turn in gender studies, Condit's project asks us to view rhetoric as a constructor of gender rather than as constructed by gender and to critique the ways public rhetorics meld gendered positions. Here, I take Condit's perspective on rhetorie and gender to the task of building a critical rhetoric narrative concerning the Brandon Teena case in order to critique a specific historical construction of gender. 
Further, rather than attempt to comment about "transgendered" subjectivities or the experience of transgenderism, I discuss the case as it was represented in a variety of news outlets, placing my primary focus on discourses available on common library research databases (e.g., Lexis-Nexis) as well as Aphrodite Jones' All She Wanted (the true crime account of the case). "My focus is on "dominant" or commercial discourses rather than marginal or individual discourses for at least two reasons: as argued above, mainstream discourses illustrate the rhetorically material ways that those who do challenge dominant ideology are ideologically disciplined, the ways gender normativity is upheld. As Kate Bornstein notes, caricatures of transgendered people are "creeping into the arts and media" (59). These are the very caricatures I analyze in this essay in asking, "How do nontransgendered people (who are not concerned with transgendered issues) configure transgenderism through mass mediated representations?"

Secondly, I keep my claims curtailed to mainstream rearticulations of gender norms because $\mathbb{I}$ want to be careful not to suggest that such a study explores transgenderism as a subjectivity. Hence, while I am sympathetic with Susan Stryker's claim that "It is no longer sufficient ... to approach the topic as Marjorie Garber did in Vested Interests, where she proceeded solely by looking at transsexuals and transvestities and the cultural gaze that both construets and regards them, with absolutely no concern for transgender subjectivity" (148), I take Stryker's claim to concern the critical community as a whole. That is, $\mathbb{I}$ assume that some readings of the case will be interested in the politics of transgendered subjectivity while others, such as this one, should focus on the constraints of the public rhetoric about transgender. ism. In short, I utilize the public discussion surrounding this case to understand one dimension of gender ideology in contemporary culture and not the position of transgendered people in contemporary culture. ${ }^{11}$

In the following sections of the essay, I provide a critical reading of mainstream discourses and argue that this is a case of ideological discipline in which Brandon Teena's gender is tied back into "sex." Again, regardless of a theoretical assumption that sees sex as always gendered or "discoursed," in mainstream public discourses, a transgendered person becomes a foil in which the presuppositions of the gender and sexual norms of contemporary culture are reiterated and reaffirmed, in which ritual and taboo operate to assure this. This reaffirmation of norms takes place in a number of ways. First, by telling the story through a narrative concentrating on deception, most news stories represent Brandon as a "real" woman who was intentionally posing as a man in order to fool others. Second, news reports and public narratives reify the physicality of Brandon Teena's body (including what Brandon does with the body) as following traditional male-female heterosexual activities. While Brandon's body is cleariy marked as female, Brandon's use of the body is marked as a successful performance of masculinity. 
Third, popular cultural discussions of the causes of Brandon's transgenderism explain the body/psyche of Brandon Teena as a caused abnormality that could have been prevented had Brandon been given proper physical and emotional care as a child. Finally, discussions of Brandon's body as either hermaphroditic or as in preparation for a surgical female-to-male transition reveal a cultural impulse to work the body into a traditionally sexed position and to align genitalia (sex) with "true gender."

Each of these themes works by positing Brandon's body and behavior as simultaneously familiar and alien, and, in this way, the overall representation reifies heteronormativity. That is, because Brandon's behaviors and appearance are illustrated as strikingly and familiarly masculine, the behavior of the women attracted to him can be configured as a "normal" expression of healthy heterosexuality. Simultaneously, because Brandon's "alien" desires and gender deception are ultimately revealed, we learn that in the end no one can fool the gender binary system. Each of the themes discussed below highlight the ideology of gender and sexuality in contemporary culture, laying bare the ways that transgenderism and gender fluidity continue to be disciplined back into binary norms.

\section{Deception in the Heartland}

Consistently, reports tell the story of Brandon Teena as, at base, the story of "deception in the heartland," a story of how a young woman deceived others about her gender in the pursuit of her own desires. $A$ cursory glance at the titles and subtitles of accounts of the case alone starkly makes this point. The subtitle of Aphrodite Jones' account is "A True Story of Sexual Deception and Murder in America's Heartland." The movie poster for the film, The Brandon Teena Story, called the film "A true story of love, hate, and revenge in the Heartland of America" ("Zeitgeist"). A lengthy report in the Omaha World Herald was entitled "Romance, Deceit and Rage" (Burbach and Cordes) while another in The Des Moines Register was "Charade Revealed Prior to Killings" (Fruhling 1). The Advocate used the title "Heartland Homicide: Smalltown Nebraska Life was fine for a 21 year old man-until everyone discovered he was actually a woman" for its first major article on the case (Ricks) and entitled its shorter follow-up "Deception on the Prairie" ("Deception"). A one act play that dealt with the case was named "Murder in the Heartland" (Delmont) and, finally, Playboy entitled its essay "Death of a Deceiver" (Konigsberg).

When told that one is about to hear a story of "deception," one expects a story with something sinister afoot, a story of a predator who successfully preys on others by keeping them from the truth. Indeed, deception implies the intent to make truth out of appearance. In this case, deception is a term that logically favors fixed notions of sex/gender 
over an ideology of gender fluidity. While there are multiple ways one could logically tell this story such that Brandon's gender would not be seen as deceptive (e.g., one could argue that gender or masculinity is performative, hence making Brandon male because he performed masculinity), the reports of this case, both those sympathetic and those unsympathetic to Brandon's position, clearly portray the story as one of deception. Given the prominence of the deception narrative, other potential ways of thinking about gender and gender identity are closed of: To say that Brandon was "deceiving others" (and was caught in the act of deception) is to say that Brandon knew he was a woman but wanted others to really think of him as a man. The deception narrative implies that Brandon actively lied to others, hiding what she knew to be her "true" sex, and acts within a traditional iteration of gender norms and desires that ultimately serves to protect and reaflim the normative heterosexist ways of making sense of gender and of disciplining gender trouble. ${ }^{12}$

Obviously, a case involving a transgendered person like Brandon Teena who was attractive to self-identified heterosexual women as a sexual partner and to heterosexual men as a friend, is interesting as a potential case of gender trouble and confusion. However, it is on the grounds of familiarity (i.e., she appeared male) and alienation (i.e., we were deceived by her) that the story is told, hence reifying rather than troabling gender norms. In short, as the examples below illustrate, rather than make sex and gender identity "messy," the story as told configures Brandon as a woman based on genitalia alone. ${ }^{13}$ Aphrodite Jones, for example, quotes Michelle Lotter, sister of one of Brandon's murderers, as saying that she believed Brandon's "deceptive" behavior indicated that she was lesbian and that the two men murdered her because both were "angry after learning about Brandon's deception" (245). ${ }^{14}$ Jones further notes that on the Maury Povitch Show, Brandon was described as a woman who "posed as a man" (258). A press release for the film The Brandon Teeno Story noted that "the catalyst for the murders was the sexual persona of Brandon Teena ... that Brandon was actually female, passing as a male and dating loca! women" (Zeitgeist, emphasis mine), Chris Burbach and Henry Cordes describe Brandon Teena in the Omaha World Herold as "chamingly playing the role of a young man" (1A) and Burbach notes that Brandon's mother testified that Brandon "started portraying somebody that she wasn't"-a male (Burbach "Prosecutor Sees"). In a single article in the Des Moines Register, Larry Frubling notes that "Brandon's charade ended in the bathroom of the small house with her trousers pulled down to her knees," "Brandon's pretense began unraveling," and "Brandon's true identity came to ight" (emphases mine).

Eric Konigsberg observes in Playboy that "posing as a man gave Heena Brandon what she couldn't get as a woman-adoring girlfiriends and a fiance. It also got her killed" (94). Not only does Konigsberg 
utilize the "female" birth name "Teena Brandon" throughout the article as Brandon's "real name," but he does so in the context of an article that makes it clear that Brandon was "posing" as male, again emphasizing gender as physically tied to genitalia (sex). ${ }^{15}$ Konigsberg's explicitness about Brandon's "deception" is highighted throughout the essay; Konigsberg notes, for example, that "Teena didn't seem to have trouble finding new people to con, new women to woo-women who desperately wanted to be charmed by a man who understood their needs. Her relationships were with girls whose ideal of a man had never been realized until they met Teena . .." (194). ${ }^{16}$ Turther, Konigsberg includes portions of an interview with murderer Tom Nissen in which Nissen said raping Brandon was an "ego thing. I felt like I'd been fucked. Me and Brandon had a long conversation that evening, and Brandon started to feed me another line ..." While clearly not offering an apology for the murderers, Konigsberg makes clear that the logic of deception was at work. ${ }^{17}$

The second half of this articulation-the Heartland in which the deception occurs-works metaphorically and semiotically to heighten the impact of the deception. ${ }^{18}$ The coupling of deception with heartland encourages us to think of Brandon's transgressions as the corruption of innocence and normality. In that "the heartland" is understood as the "normal," "average," and most purely American segment of the nation, Brandon's deception of numerous young "midwestern" women is represented as particularly vile. Transgendered deception is more than the deception and corruption of individuals here; it is the deception and corruption of the heartland of America.

\section{Teena's Female Body, Brandon's Masculine Performance}

\section{Body, Play, and Clothing}

Kate Bornstein argues that while there could potentially be "as many types of gender as could be imagined," Western society has culturally taken on "sex" (as in genitalia) as a sign of gender, and hence enables us to utilize visible cultural markers to make judgments about each other's sex and proper public behavior (30). Alice Dreger similarly observes in her history of hermaphroditism that a "one body, one sex" logic has ensued over the last several centuries, with the presence or absence of gonads being determinate of gender/sex in the medical arena and the assumed presence or absence of gonads being the grounds on which proper gender behavior is judged publicly (109). ${ }^{9}$ Indeed, rhetorically, gender still works along a male-female binarism in mediated accounts, and the discourse surrounding the Brandon Teena case illustrates that gender is tightly articulated with genitalia on a rhetorical and ideological level. 20 Discussions of Brandon's body continue to employ a sex-gender split with multiple reports pointing to the body of Brandon (i.e., the genitalia) as proof positive of Brandon's "femaleness" 
while simultaneously observing that Brandon's physical appearance and behavior were marked by masculine signifiers. Whether Brandon is represented as particularly adept at understanding how to act like a "ratural man" or his masculine behavior is explained as a psychic or physical defect, Brandon is posited as "physically" a woman who learns (or is compelled by defects) to perform behaviors that are naturally those of men. By pointing out the genitalia that made Brandon "really" a woman and the activities that made Brandon "appear" to be a man, the signifiers of masculinity and femininity are reified, the binarisms held intact.

Here, then, I pay particular attention to those behaviors and physical features employed as evidence of Brandon's "masculinity" or Teena's "femaleness." I should emphasize that I am not questioning the veracity of the claims and observations being made (nor, of course, am I verifying them). Rhetorically, what is significant is that particular behaviors and signifiers are consistently reported and reified, whether they occurred or not, indicating the importance of these behaviors as elements of the iteration of gender norms within contemporary U.S. culture. In turn, I discuss the discourse that outlines Brandon's gender and genitalia, Brandon's behavior and aesthetic as a child and as an adult, his physical appearance as an adult, and, finally, his (heterosexual) physical activities.

First, then, examples of the coupling of Brandon Teena's "real" gender with Brandon Teena's genitalia are ubiquitous and work hand in hand with the deception metaphors discussed above. For example, when Aphrodite Jones opens her account of the case, she notes that Brandon had told a friend that "he was really a female, that he had female parts" (105). One of the most striking examples of the equation of gender with genitalia occurs when Jones reports that on the night when Brandon was eventually raped, Lotter and Nissen had become increasingly dissatisfied with Brandon's explanation as to his gender and "after awhile, ... the guys decided they needed someone to see this guy's cock or else" (208). Elsewhere, The Advocate report on the case notes that Brandon was "actually a woman" (Ricks 28).21 In each example, Brandon Teena is posited as having a "true" gender which could be evidenced by genitalia (in effect, the lack of a "cock") and a deceptive one (insofar as one cannot be male without a penis).

In terms of male/female activities, Brandon's behavior is often examined through references to his/her behavior/dress as a child. In general, when the story of Brandon's youth (as Teena Brandon) is recounted, it is a narrative that suggests that while Brandon was physically a gir! and should have developed "feminine behaviors," he developed masculine behaviors as a result of an aberration (as I will discuss below). When Jones focuses on the story of Brandon's childhood and that of his sister, Tammy, she sets up a pattern of descriptions that persistently emphasizes the differences between Tammy's femininity and Brandon's 
maseulinity. First, femininity and masculinity manifest in the clothes each liked to wear and in how each liked to play. While feminine Tammy decorated her room with stuffed animals and dolls, "Teena collected things-stop signs, beer signs, whatever" (32). While Tammy wasn't especially found of insects, one of Teena's favcrite activities was to "place snakes in a lunch box and throw the snakes and a collection of bugs at Tammy" (32). While Tammy played with dolls, Teena "mostly played with sturdy things like Tinkertoys and Lincoln Logs. She liked to construct and destroy" (32). Tammy enjoyed wearing "frilly little flowered dresses and lace ankle socks; Teena was always in T-shirts, jogging shorts, and unsightly boy's tube socks, the kind trimmed with red and blue stripes" (33). Tammy wore makeup while Teena refused (33). While Teena was forced to wear dresses for pictures, she tried to tear them off (33-4). The Omaha World. Herald observes that, as a child, Brandon "preferred playing with a garter snake to playing with a doll. She preferred taking an old radio apart to doing her hair. Rather than dress up, she would just as soon play basketball" (Burbach and Cordes). ${ }^{22}$ Similarly, Playboy's Eric Konigsberg notes that Teena, "awkward and impish," rebelled against her school's dress code by "wearing pants and a tie. She kept her hair short and told people she was allergic to makeup. She was into weight lifting" (94). In The New Yorker, John Gregory Dunne repeats the snake stories told by others and adds that Brandon had a "secret desire" to become her school's quarterback (50). In each description, the details work to emphasize the signs of masculinity and femininity. It is not just that Tammy wanted to wear dresses, she wanted to wear "frilly, little flowered" dresses with lace ankle socks. Brandon did not simply want to wear shorts and T-shirts but jogging shorts and those "unsightly" tube socks with stripes. The masculinity here is one of spiders and snakes, beer and cars, and unsightly athleticism versus a femininity of frilly fowers and lacy ankles, domestic dolls and stuffed animals. Regardless of the "essential" or cultural assumptions about gender being made by those describing it, the descriptions ultimately provide a reifying crystallization of cultural expectations of gender normativity.

Descriptions of Brandon as an adult also focus on specific clothing choices and body movements as signifying masculinity. For example, in terms of Brandon's style choices, Minkowitz observes that Brandon was buried in "men's clothing, wearing her favorite cowboy shirt and black cowboy hat" (24). Ingrid Ricks similarly notes that Brandon "dressed in men's clothing, often Western wear, and wore her dark brown hair close-cropped" (29). Dunne observes in the New Yorker that Brandon died dressed as a man, in "black jockey-style underwear, sweat shorts, a sweatshirt, a T-Shirt and sweat socks" (46). Whethor rugged cowboy or jock, Brandon's clothing is consistently used to signify his masculinity. 
In addition to his clothing, Brandon's physical appearance is articulated onto specific icons of American promiscuous masculinity. For example, Minkowitz notes that after Brandon arrived in Fals City, every young woman in town was "after this pool player with the jawline of a Kennedy" who gave gifts with "Elvis-esque extravagance" (24) and goes on to observe that in one photograph Brandon looked "Tike JFK, at once serious and mischievously conscious of his grood looks" (26). Aphrodite Jones makes a similar observation when noting that when a young woman named Heather had her first kiss with Brandon, she did so because "she was bowled over by his slick crew cut and Kennedy jaw line" $(58) .23$

Again, these descriptions of clothing and dress, coupled with the overall assumption of Brandon as deceiver, pick at at cultural concern with being "fooled" about "true gender." Rather than allowing for gender ambiguity or for a configuration in which Brandon was male because he identified as male, we are led to understand that Brandon was able to deceive because "she" so clearly utilized hypermasculine signifiers. As a whole, the discourse draws out the signifiers of masculinity to explain the gender confusion experienced by those who encountered Brandon Teena. As Marjorie Garber might note of this discourse, "It is as though the hegemonic cultural imaginary is saying to itself: if there is a difference, we want to be able to see it, and if we see a difference (e.g., a man in women's clothes), we want to be able to interpret it. In both cases, the conflation is fueled by a desire to tell the difference, to guard against a difference that might otherwise put the identity of one's owr position in question" (130).

\section{Urination and Heterosexualidy}

This same ideological work to restabilize gender signifers is evident in questions about Brandon's physical and sexual behaviors. In brief, physically, the signifiers of Brandon's masculinity as crystalized in public recountings of the case range from the way he urinated (standing, of course) to his heterosexual behavior with women. While Brandon is configured as a lesbian in some accounts of the case ("Fierce" 27), What is important here, and what I llustrate below, is that most discussion about the case provides a lens through which to see the expected "iteration" of masculinity and femininity within heterosexual expectations. Because the discourse explains how women were "deceived" by Brandon, it also implicitly reassures us that our readings of masculinity and femininity are generally correct.

Questions about the movements and appearance of Brandon's body are generally centered on questions of how those who were intimate with him were "deceived." Aphrodite Jones attempts to explain how Lana Tisdel, one of Brandon's last girlfriends, could have possibly thought that Brandon was "really" male; Jones notes that Tisdel claimed in conversations with others that she had indeed felt a penis 
when she had engaged in sexual relations with Brandon, and "she had sworn she'd seen Brandon stand up and pee ... Even Tom (Nissen) had seen Brandon stand up and piss at one of the urinals at the Oasis [a local bar], so ... that part of the story seemed real" (209). In the New Yorker, Dunne makes a similar observation: "Brandon moved from Humboldt into Linda Gutierrez's house, and Lana Tisdel's bed. The sex was good, Lana reported, and Brandon stood up to pee" (54). Moreover, Donna Minkowitz notes that women told each other that Brandon had a penis because they had "seen him pee!" (28). What is important here is the impulse for those writing about the case to explain how the "difference" between male and femaleness was missed. As Lacan notes about "urinary segregation," despite all the differences that males have with each other, and despite all the differences that females have with each other, we culturally take the act of urination to signify that in this act, all men are equal, as are all women (cited in Garber 13-17). That Brandon's "standing up to pee" is so often raised in the discourse of the case works simultaneously both to destabilize urination as a marker of the essentiality of gender and to reaffirm its status as one way such difference is publicly signified. That is, the evidence is raised to explain how women were fooled, hence destabilizing the sign, but simultaneously reaffirms that it is one way to keep gender straight and binary. Moreover, while Brandon may have been able to use this signifier to "deceive" his peers for a time, in the end, the story reveals, the truth of gender wins out.

Somewhat similar observations can be made of the coverage of Brandon's sexual relations and the way his physical relations with women troubled heterosexual norms. Regarding contemporary observations that heterosexuality has "made a comeback" in popular culture, Lauren Berlant notes that "Nowhere in the United States has heterosexuality gone into a decline or 'left' in a way that makes the idea of a comeback even remotely possible" (16). The discourse surrounding this case highlights the ways the assumption of heterosexuality continues as a dominant theme in popular culture. In particular, this is so not because Brandon's sexuality is denigrated (or even the primary focus) but more because one of the primary implied themes of the discussion is the protection of the sexual identity and sexuality identity of those "fooled" by Brandon. In protecting the "deceived," the discourse protects cultural norms as a whole, assuring all of us that the iteration of compulsory heterosexuality remains stable regardless of the misidentifications in this particular case. Rather than Brandon and his partners being positioned as engaged in queer or transgendered sexuality, the public discussion persistently confirms that those who were engaged in sexual relations with Brandon were themselves practicing what they thought to be normal heterosexuality. Again, referring to Marjorie Garber's claim that the desire to see and know gender differences is an impulse fueled by a desire "to guard against a difference that might 
otherwise put the identity of one's own position in question" (130), this public discussion upholds normalized iterations of heterosexuality. While I do not want to discount the possibility that for particular individuals the case destabilizes gender identity and sexual desire by recognizing that heterosexual masculinity is performative, I do want to suggest that the case works discursively to protect heterosexuality both by allowing Brandon's "girlfriends" to remain heterosexual and by emphasizing that Brandon's "Iack" ultimately undermines the heterosexual masculine performance. Brandon's temporarily successful performance of heterosexual masculinity does not destabilize gender binarism or heterosexuality because it ultimately does not trouble masculinity or femininity.

Marjorie Garber notes that in public discussions of the case that inspired $M$. Butterfly, the one question that was raised repeatedly, almost obsessively, in the public sphere concerned sexual relations between the two men: "What did they do in bed?" (236). This same fascination predictably follows Brandon and his paramours: not only "what did they do in bed" but "how were the women persuaded to get into bed with Brandon in the first place?" This question is most generally answered in narrative form, a story beginning with a discussion of Brandon's dating behavior. Repeatedly, Brandon is referred to as the perfect gentleman, the ideal man, with this ideal masculinity being drawn within heterosexual romance narratives. Aphrodite Jones quotes Heather, Brandon's first girlfriend, as observing that Brandon would be any womar's dream guy: "He knew how a woman wanted to be treated ... He took you out to dinner, bought flowers, roses, just everything" (61). Jones also observes that Brandon's one time finacé asserted that Brandon was the "perfect gentleman," always taking her out to eat, opening doors for her and never allowing her to pay for anything (100). The Denver Post observes that numerous people described Brandon as "a dream suitor. She (sic) showered them with gifts, showed them respect and swept them off their feet" (Will). ${ }^{24}$ The San Francisco Chronicle begins a story by observing that "There wasn't much that Brandon Teena didn't know about pleasing a woman. His girlfriends praised his courtiness, his sweetness, his generosity" (Guthman). Even Brandon's "less gentlemanly moments" are consistently described by those women quoted as behaviors that made him "a normal guy." Jones quotes one of his girlfriends as saying Brandon "was a pervert, just a regular guy, always making jokes" (126). In The Advocate, Brandon's final girlfriend (Lana Tisdel) notes that Brandon "was like a normal guy. He talked like one; he acted like one" (Ricks 29). In each case, we learn that Brandon was successfully able to seduce women because he was able to so successfully perform heterosexual masculinity.

Furthemore, because so many women reported having sex with Brandon, the performance of the act itself is a matter of obvious confict throughout the discourse. Once again, Brandon is posited both as the 
perfect man (i.e., the familiar-his attention was on the women without pressure) and as simultaneously not a man (i.e., the lack of a penis). Jones notes that one young woman claimed to have received her first orgasm from Brandon during oral sex and quotes others remarking on Brandon's stamina during intercourse (269-270). Konigsberg notes that Brandon provided many of the women with their first impression of "What all the fuss was about," that sex was not simply something to be done for their boyfriends (194). Konigsberg quotes one woman as observing that, after her first time with Brandon, "I don't think there was a time with him when I didn't come,' the girl said, 'orally, going all the way, even dry humping.' "(194). Further, Dunne relays stories from women who claimed to have to go on the pill because of sex with Brandon (51) and Minkowitz observes that "every former girlfriend . . said Brandon was "the best lover" they ever had" (24).

This consistently repeated evidence of Brandon's sexual prowess and success could obviously complicate normative understandings of gender and sexuality. However, the irony that the ideal man had female genitalia, an irony that could destabilize gendered meanings, ultimately works instead to reify them. Rather than stress gender trouble, the body of discourse consistently suggests that heterosexual women were fooled because Brandon performed masculinity so well. It is significant, then, that many of Brandon's girlfriends are quoted as noting that Brandon was able to deceive them sexually either because he used a dildo or because he performed oral sex without reciprocation. For example, Dunne observes that Brandon's early girlfriends thought he was an expert kisser and that they could have sex with him and think he was a male because he either "stuffed socks into his shorts" or would "wear a dildo" (50). The problem again is one of maintaining strict boundaries between male and female while leaving heterosexuality untroubled. While Brandon's sexual success cannot help but somewhat trouble gender normativity, public discussion of the case maintains that the women were fooled and hence were, in their own minds, performing heterosexuality, and that Brandon's deception would ultimately be discovered.

We find a number of examples of ways the woman who had sex with Brandon are allowed to "confess" their heterosexuality after the fact, redeeming themselves rather than rethinking sexuality and gender as performative. Because the deception metaphors discussed earlier work to protect heteronormativity for those who were "fooled" by Brandon, they should also logically indicate potential lesbianism on Brandon's part (i.e., Brandon fooled others into thinking he was a man when he was actually a woman having sex with other women). However, not only is Brandon's voice recuperated to ward off lesbianism, but so are those of the women who slept with him. In the clearest example of this configuration, Lana Tisdel is quoted in Minkowitz' article as repeating two mantras to help her understand the experience: "1. When I kissed 
Brandon, I wasn't kissing a woman, I was kissing a man; 2. Brandon didn't love the way a woman loves a woman, he loved me the way a man loves a woman" (27). Minkowitz skeptically notes that while Tisdel cannot explain what difference such a mantra meant, she adamantly wanted to be considered heterosexual (27). Minkowitz also observes that Brandon's former fiancé, Gina Bartu, "freaked out" when she was in a gay bar with Brandon and had the sense that people might think she and Brandon were a lesbian couple (26). The only sexual configuration allowed in such discourse is a heterosexual one; there is no fluidity in these descriptions. In a sense, as has been illustrated throughout this section, the only two options that appear to be allowed are based on gender binarism rather than on, for example, Kate Bornstein's description of stylistic differences which would configure Brandon and his girlfriends as something other than either homosexual or heterosexual (32).

While Brandon's girlfiends are protected from the lesbian label because of the deception narrative, Brandon's desires could easily he coded as lesbian ones. However, Brandon's fear of, and disgust with, lesbianism is reported repeatedly, reaffiming his own investment in gender binarisms. Jones reports that Brandon once had a confrontation with her mother over her sexual identity, and Brandon insisted that lesbians were "disgusting" (68-69), ${ }^{25}$ Burbach and Cordes note in the Omaho World Herald that Brandon's mother observed that Brandon "told me she wasn't a lesbian and was very adamant about that. She didn't want to be with a female in that way." Konigsberg notes that Brandon did not attend "gay parties" if many lesbians would be attending because Brandon found them disgusting (193). Minkowitz pursues this theme strongly, noting both that Brandon had told a high school classmate that she was "disgusted by lesbians" and that she was going to "love women like a man" (28). While it is certainly the case that the idea rarely arises, as Hale observes, "that the words female bodied and woman might not be coextensive with regard to some people's selfidentifications" "Consuming" 315), here all the evidence brought to bear is situated to work firmly within gender binaries and heteronormativity. Given a paucity of ways to think, the potentially transgressive and blurry configuration of Brandon's gender/sexuality is ultimately tied down in binarisms as is his sezuality (i.e., Brandon is homosexual if we take the body as gender and heterosexual if we take into account her self-identity). There is no public blurring of sexuality and identity; it is clearly one or the other for both Brandon and Brandon's partners in the configuration allowed by public discourse. What we have seen to be the case with play, clothing, and style, then, is true of sexuality as well-the disconrse around Brandon Teene's sexual activities and desires reactivates heterosexual norms. 


\section{Brandon's Body: Attitude of an Hermaphrodite ${ }^{26}$}

Marjorie Garber notes that it is paradoxically the case that transsexuals and transvestities are more concerned with maleness and femaleness than persons who are neither transvestite nor transsexual (110). While I have illustrated this to be the case in the discourse alleged to have been spoken by Brandon Teena and the public discourse about Brandon Teena's activities and appearance, another interesting aspect. of this case concerns the way Brandon's troubled body is talked aboutboth by Brandon (reportedly) and by others. In the multiple narratives of the case, stories consistently recount times when someone "discovered" that Brandon did not have a typical male body, placing Brandon in a position of having to explain what "he was" Either because Brandon actually thought in these terms or because the pressure of his audience forced him to speak in these terms (or because those reporting the case could only work within certain dynamics), Brandon is reported to have consistently discussed his body in such a way that he clearly saw the penis as the marker of "maleness" or manhood. Brandon's two responses-to posit himself as an hermaphrodite or as a preoperative transsexual-focus on the penis and its importance to being a man. I should point out that while Brandon's words as quoted seem to have more of a transgressive tone to them, at times indicating his own ability to see a disjuncture between body and identity, the reports about the case generally push back in a direction in which body and identity are articulated together.

Given a lack of vocabulary to describe oneself as "transgendered," Brandon reportedly described himself on more than one occasion as a hermaphrodite awaiting surgery (Dunne reports that Brandon got the idea from an episode of Montel Williams) (50). Jones notes that Brandon told Heather, his first girlfriend, that "he was a hermaphrodite, born with both sexes, that he was raised as a female" and was planning on having an operation to make himself completely male 63 ; see also Ricks 29). The Omaha World Herald observes that "When questioned about her sexuality, Miss Brandon told people she was a hermaphrodite, a person with both male and female sex organs" (Burbach and Cordes; see also Wheelwright). ${ }^{27}$ Further, Dunne notes that this was the same story Brandon told his earliest girlfriends (50; see also Minkowitz 25) and that each time, he made it clear that he would someday become completely male. Alice Dreger notes that modern medicine has developed an attitude about hermaphroditism that forces hermaphroditic bodies into one of the two "natural" sex categories based on particular aspects of what the person has (the "One body-one sex" rule). ${ }^{28}$ Evidently, in the case of Brandon Teena, this understanding translated into his own need to confine his body to one sex rather than to understanding gender itself as fluid or as not related directly to the body. If that body was hermaphroditic rather than female, Brandon 
could take the attitude with others that the body was genuinely male, that it came equipped with a "real" penis.

The second explanation offered about Brandon Teena's gender is that he was a preoperative transsexual. Jones, for instance, notes that when his mother told his irst girlfriend that he was neither a male nor a hermaphrodite, Brandon confessed he felt like a man inside and wanted to have a full sex change operation (81). Perhaps more telling culturally, many news articles began their discussion of the case with a blography of Brandon Teena that states this preoperative narrative as fact. For example, one story begins, "Brandon Teena, whose birth name was Teena Brandon, was originally from Lincoln, Nebraska, and moved to nearby Humboldt in 1993 , shortly after beginning to live full-time as a man in preparation for eventual sex-charge surgery" (despite the fact that Brandon is never reported to have had solid plans to have surgery) ("Brandon Teena Murderer"). Burbach and Cordes note that Brandon told people "She was a transsexual in the process of getting a sex change." Further, Ed Will observes in the Denver Post that Brandon told others that she was either "considering or had had sex-change surgery" while Konigsberg notes that Brandon called himself a preopexative transsexual and claimed he was having trouble raising the funds to complete the operation (see also Minkowitz 26). Jay Carr of the Boston Globe takes the claim that Brandon was in the process of a sex change as factual, noting that Brandon had "begun a series of sexchange operations by the time she moved from Lincoln" (see also "Best").

In short, both the hermaphrodite and preoperative discourses put heavy focus on the penis as a natural sign of masculinity and malehood, reinscribing the gender-as-sex ideology. Whether positing himself as a hermaphrodite or as a preoperative transsexual, Brandon Teena, and reports about Brandon leena, work within the same gender constraints that we all are faced with. To be male demands the presence of a penis, and Brandon was metaphorically adding one with either rhetorical strategy.

\section{The Causes of Aberration}

In her history of hermaphroditism, Alice Dreger notes that while hermaphrodites' mothers have traditionally been considered by medical personnel to be "poor witnesses with regard to the 'sex" behavior of their 'doubtful' children, they were frequently expected to account for the deformity in their offspring," to explain the cause of the unnatural body (71). What is significant, as transgender activists continually point out, is that hermaphroditism is natural in the sense that it is the 'matural body' a person is born with. ${ }^{29}$ Hence, surgical changes to a body to make it more closely resemble a male or female body could logically be seen as acts of deformation. In similar fashion, one could argue that 
Brandon Teena's identity and desire are as "natural" as anyone else's. Nonetheless, in the case of Brandon Teena, multiple threads work to configure Brandon's transgendered body as an aberration, a mistake that could have been prevented. In general, bodies are forced into male/female categories; once in these categories, they either need to properly perform (i.e., perform according to gender norms) or the search is on for the causes of their "malfunction." This is precisely what occurs in discussions of Brandon's body. While few of the essays and articles surrounding the case make an explicit claim to understand the "cause" of Brandon's sexual identity, it is an underlying theme throughout. While one would never expect to find attempts to explain the cause of a person's heterosexuality, the "cause" of Brandon's gender and sexuality ambiguity is discussed as a matter of routine.

In the most general terms, Brandon's "transgenderism" is posited as resulting from either a chemical/physical imbalance (e.g., "extra hormone shots during pregnancy") or from psychosexual abuse at an early age. In both cases, Brandon's mother is at least partially implicated as part of the problem that led to Brandon's "condition." In terms of a chemical imbalance, Aphrodite Jones at several points suggests that problems during Brandon's gestation may have been the cause of his nontraditional desires. Jones quotes Brandon's mother JoAnn as saying that during the early portion of her pregnancy with Teena, the uterus was not growing at a sufficient rate and had not "tipped" as it was supposed to, so her doctor "gave me hormone shots or something, and they were so thick, a thick serum... I went through this for two weeks, and then she started to grow ..." $(27)$. As this telling of the story unfolds, it becomes obvious that one way of reading the story, of understanding Brandon's aberrant condition, is to see it as resulting as a mistake in the hormone process. If Brandon had been able to grow as the body intended, this condition would not have occurred.

Secondly, there are a number of intimations of Brandon's having been sexually abused as a child with this abuse linked to her transgenderism. Jones claims that Brandon disclosed this sexual abuse to his first girlfriend (63) and that, during a therapy session after a suicide attempt, told the counselors about "hours of sexual abuse in her childhood and adolescence, saying that she felt intimidated by certain men, that she always felt sexually orientated toward women" (83). Minkowitz quotes Brandon's sister 'Tammy as asserting that Brandon was unhappy as a woman because "we were both molested by a male relative when we were little" (29). JoAnn, Brandon's mother, upon hearing about the sexual abuse during the counseling sessions, is reported by Jones as observing that the abusive relative had "destroyed Teena, and that was why Teena wasn't interested in men" (86). Konigsberg also situates the story of Brandon's having been raped and abused at the center of her transgenderism (193). Dunne, in perhaps the clearest example of this form of causal reasoning, makes note of 
Brandon's sexual molestation and observes that somewhere in all this, "there might be an early clue, a first carse, a reason that would make Teena's subsequent ventures across the gender divide easier to accommodate" (italies mine, 50 ).

Whether chemical or psychological, rather than taking Brandon's icentity as "natural," we see here a search for the cause of the anomaly that encouraged Brandon to act outside the realm of normal behavior. While no cause would have been searehed for if Brandon had not been transgendered, here the search for a cause seems vital. If gender operates on iterated norms, cases of transgression must be explained. More, and this is significant in terms of parental roles-particularly those of the mother-in both cases, the mother is partially implicated as responsible for the problem either because of hormones taken during pregnancy or for not having done enough to circumvent the physical and sexual abuse.

\section{Conclusions}

The public iteration of the Brandon Teena story provides us with a number of observations about doxastic understandings of gender/ sexuality. I will begin with observations drawn directly from this case and then provide observations on the direction/purpose of criticism from a gender diversity perspective. First, I want to be clear that the discourse studied here is part of a cultural ideology that affects all of us; it is a discourse that is defining, disciplinary, even while we negotiate within its boundaries. As Leslie Feinberg notes, everyone is constrained by the same body of public argument; hence, critical readings of the disciplinary discourses about transsexualism, transgenderism, or intersexualism are simuitaneously critiques that help everyone understand their own interpellation within gender and sexual discourses (92). ${ }^{30}$ Hence, those discourses that shape the ways Brandon Teena was understood are the same discourses that shape each of us, the same discourses that reiterate gender norms and their influence. While I assume that these discourses could be read transgressively or "against the grain," they are the discourses with which all of us must negotiate and hence should be everyone's shared critical responsibility.

Second, when a subjectivity is either not represented (symbolically annihilated) or represented negatively, those people, including adolescents, who are developing a similar subjectivity are more likely to do so relatively alone, without the idea that a supportive community might exist. While this can have tragic implications in cases of adolescent homosexuality, as Kielwasser and Wolfe have pointed out, it is surely more of a problem with transgendered indivicuals, as Leslie Feinberg poignantly observes in the opening of Transgender Worriors. Maturing in a world that either does not acknowledge one's existence, or degrades the subject position one wishes to "take on," would certainly make one's 
path difficult. ${ }^{31}$ Obviously, critical work that underscores the "naturalness" of transgenderism and highlights the complexity of desire would be in service of those whose desires and identities are outside of cultural norms.

Third, despite the fact that numerous contemporary theoretical voices posit an already existing blurring of gender categories, the Brandon Teena case is one site where the meaning of gender in dominant culture remains fairly constraining. Not only do we find it in the signifiers of masculinity and femininity that lace this discourse and in the metaphors of "deception," but it also exists significantly in the idea that transgenderism is an abnormality. As the opening epigram indicates, there cannot be a blurring of gender/sexual categories when that blurring makes sense of a large array of subjectivities by understanding them as a form of deformation or when so many discourses continue to discipline transgenderism into a system of bigender heteronormativity. Hence, it is not only that the experience of transgenderism is negatively represented, but that gender and sex are "talked about" in ways that are radically limited. Hence, when Brandon Teena is situated discursively, he becomes "really" a woman, "really" Teena, because of his "female body." The way that body is allowed to desire works along the same axis of male-female body types (rather than, for example, as Bornstein suggests, style) and along the lines of homosexual and heterosexual desire.

Finally, I am not trying to suggest that "male" or "female" and heterosexual are not categories under which some individuals want to constitute themselves. However, it is the case that the discourses surrounding this case, a case very open to numerous possibilities to refigure gender and sexuality, instead fold it back into a traditional iteration of heterosexual normativity. As C. Jacob Hale notes in his brilliant essay on the Brandon Teena case, we would be wise to recognize that borders and categories are necessary as starting points. In short, while Hale sees the need for categories on which to base identity, he argues that these borders must be refigured as creatively contingent (338). ${ }^{32}$ As $I$ argued earlier, the first step in making this move, and a step that this essay adds to, is to reenvision rhetoric as a constructor of gender rather than as constructed by gender (Condit "In Praise" 110) and to pursue criticism that builds upon this understanding of the relationship of gender and rhetoric. In criticizing the logic of heteronormativity in particular cases, we open the door for the possibility of a variety of ways to "talk about" gender and sexuality.

\section{NOTES}

II will cite the news sources as they are utilized in the essay. The Guggenheim art project, entitled "Brandon" can be found at http://orandon/guggenheim.org. The film is The Brandon Teena Story, directed by Susan Muska and Greta Olafsdotir, distributed by Zeitgeist Fihms. For discussions of proposed films and plays, see Minge; Moton "Documentary;" Moton "Story;" Moton "Film;" Burbach "3 Judges;" "Murder;" Delmont. 
"Throughout the paper, I will refer primarily to "Brandon Teena" and hence will often be using the masculine pronoun. There will be times in the paper, however, when I will either be quoting others who talk about Brandon as a woman or when I am discussing her as female (e.g., when working through stories of her childhood). At such times, the feminine pronoun will be employed. I mark such moves as clearly as possible.

${ }^{3}$ I am retelling the story as I would in a face to face interaction rather than by looking back at any given essay or book. One conld look at any of the sources I cite in this essay to get a similar telling of the story. Aphrodite Jones' true crime book is the fullest treatment.

4 of course, as Leslie Feinberg has pointed out in Transgender Warriors, transgender activism has a long and varied history under a number of different names. However, the Brandon Teena case and the activism surrounding it did take transgender activism to a much broader public level, especially given the vocal presence of activists at the trial. $A$ good web resource that allows one to follow in narrative from some of the activism that trok place around the trial is the FTM International Website (http:/ www.ftm-int.org/).

5The more contemporary term for hermaphrodices is "interseged." To a large degree, am using the term hermaphrodites in this paper because it is the term commonly used in public arguments, and it is the impact and implications of public arguments that $I$ am investigating.

"If one can point to a celebratory period in Judith Butler's work, it would be in Gender Trouble when she notes the ways in which examples "that fail to comply with the categories that naturalize and stabilize that field of bodies for us within the terms of chitural conventions" significantly upset the meanings that are said to inhere within sexed bodies (110). Another clearly celebratory reader, at least at times, is Kate Bornstein in Gender Outlaw. However, even here, while Bornstein might celebrate the position of the gender outlaw those who are neither man nor woman but can be fuid between positions) in a fashion that makes sexual binarism appear is if it is easily waved away, she is well aware that multiple cultural and ideological pressures (and people enacting these pressures-gender defenders) work to keep our gender binary house in order (71-2). One could also see Judith Haberstam's Female Masculinity in which her interest is in maintaining some of the "spaces in which gender difference simply does not work right now," to "hasten the proliferation of alternate gender regimes in other locations" (4I).

"While I will not draw upon them by name heavily throughout this essey, my theoretical assumptions about thetorical materialism are heavily influenced by recent works by Ronald Greene and Celeste Condit (1994). I am also infuenced by Lauren Berlant's The Queen of America Goes to Washington City in which she notes that she is studying mainstrean documents and discourses because they should not be seen as white noise but as powerful language, not mere fiction but discourse with material effects, of ten violent material effects (13).

8If I were to put my project in conversation with Elliot and Roean's discussion of the need for' both a psychoanalytic take on the 'role of the unconscious ir the formation of subjectivity." and an historians' approach of the social regulation of subjects, I an clearly pursuing the social regulation af subjects.

"While the "critical rhetoric" unbrella of refinements is now wide reaching, I would note that I see my project as one of drawing together news "fragments" in order to create a critical narrative that can act within the larger body of discourses about this case and ahout gender in general. The founding essays of "critical rhetorie" are those by McFerrow and McGee.

10I searched using ProQuest Direct to get access to major publications and resources. I also used Lexis-Nexis to uncover over 100 newspaper articles dealing with the case, both locally and nationally. To large extent, $I$ am allowing the combination of Proquest and Lexis-Nexis to determine what are "dominant" discourses about the case. I assume that there is some space for argument over these sources, but $I$ also assume that my overall reading of this discourse is fairly consistent across all of the material with which I worked. While I also took a look at web resources, I'm a bit more selective in my use of them, as I am trying to get at discourses available in the public sphere through "commercial" outlets. While I will discuss some of the discourse of advertisements for, and reviews of, The Brandion Teena Story from the web, I will not discuss the namatives of 
those transgender activists who attended the trial of John Lotter or Tom Nissen. That discourse, as well as much popular discourse, has been analyzed in a brilliant essay by $\mathrm{C}$. Jacob Hale, "Consuming the Living, DisRemembering the Dead."

${ }^{11}$ In large part, I am taking my cues on how to proceed with this analysis by observing a particularly pointed set of "rules" about wrieing in this area: C. Jacob Hale's "Suggested Rules for Non-Transsexuals Writing about Transsexuals, Transsexuality, Transsexualism, or Trans - (http:/www.actlab.utexas.edu/ sandy/hale.rules.htm). One of the points most pertinent to my analysis is Hale's claim that such writing should not attempt to tell transgendered people about transgendered subjectivity but should instead work to note what the discourse tells about nontransgendered people, about dominant understandings of transgenderism and the way that gender ideology works in part to constrain all of us, regardless of our gender identities or sexual desires.

12This is not the case in many of the online reports authored by transgender activists who attended the funeral. While they may have had an interest in "essentializing" Rrandon as male, as Hale observes, they clearly did not posit what was occurring as a case of deception.

${ }^{13}$ should point out that every news report found through my Lexis-Nexis search referred to Brandon as "Ms. Brandon."

14For other examples of discussions of people's claims about anger due to "lies and deceptions," see Fruhling; Keenan; Strawbridge; Grubrenya; Ebert.

"FFor other examples of this "posing" or "masquerade" metaphors, see Burbach and Cordes; Burbach "Officer: Sheriff;" Burbach "Jury Told;" Burbach "Tight;" Burbach, "Mothers;" Burbach, "Jury Convicts;" Burbach "Jury Chosen;" Burbach "Ex-Girlfriend," Powell; "Prison;" "Second;" Moton "Story;" Moton "Film;" Burbach "3 Judges;" Will; Wheelwright; Wade; Boellstorff; "Murder;" "New Trial;" Hartl; Gabrenya; Hammel; Dunne; "Woman;" "Crossing."

${ }^{16}$ Konigsherg also quotes one of Brandon's former girlfriends as saying "I just couldn't understand why a girl would trick you into that if she knew you liked the opposite sex." again implying that Brandon was the same sex as the girlfriend (194).

${ }_{17}$ Michelle Lotter, one of the murderer's sisters, makes a similar claim in an article in The Advocate (Ricks 30). For usage of the phrase "true sex" to refer to Brandon Teera as a fernale, see also Burbach and Cordes; "Dateline."

${ }^{18}$ In addition to the headlines using "heartland" cited above, see Will.

19While Dreger is discussing the historical treatment of hermaphrodites, Suzanne Kessler has cogently argued that this same logic operates today in that those physicians who treat intersezed children often begin with the assumption that these children should be surgically transformed into males or females. There is no space for ambiguity. Furthermore, Dreger begins her history in a period that would follow Thomas Lacquer's period of the "one sex" model and hence the logic of her history fits well with his.

${ }^{20}$ The actual terms "sex" and "gender" may not be employed although the notions that they generally represent are certainly put into action.

21Similar observations are made in the Los Angeles Times' review of The Brandon Teena Story (Thomas F16). See also Brucker-Cohen; Minkowitz.

${ }^{22}$ Burbach and Combes go on to note "Miss Brandon's hair usually was cropped short in front and long in the back. She liked to wear sweaters, turtlenecks, button-down shirts and casual slacks." Other examples of this clothing/make up articulation can be found in Wheelwright.

${ }^{23}$ For other examples of this masculine icon articulation, see Will; "A Brief."

${ }^{24}$ For other examples of "dream guy" discourse, see Wheelwright; Bernard; Carr; Taubin; Ebert; Atherton; Boone.

${ }^{25}$ What is significant is not that Brandon Teena made this statement but that the statement gets worked into every account of the case.

${ }^{261}$ am playing off of "Hermaphrodites with Attitude," the activist group headed up by Cheryl Chase. For a discussion of the group, see Chase's recent essay in GLQ.

${ }^{27}$ For more articulations of Brandon as an hermaphrodite, see Konigsberg 194; Elliott; Atherton; Bcone. 
${ }^{28}$ Again, for a full account of such thinking amongst physicians today, I would highly recommend Suzanne Kessler's Lessons from the Intersexed.

290ne should see Chase (1998) and Kessler (1998) on this point.

${ }^{30}$ Similariy, Kate Bornstein tells the story of a heterosexual man who noted after one of Bornstein's book readings that while he had no idea what it felt like to feel transgendered, her presentation forced him to think about the pressures that constrained him as a man. The point being that critiques of any public representations of cases concerning gender/sexuality are useful to everyone, regardless of their gender and sexuality.

${ }^{31}$ As Seinberg puts it, "Every single child today-no matter how their sex or gender is developing-needs to know about these militant battles and the names of those who led them" $(81)$.

32Such a call for the production of new identities, to encourage the production of new taxonomies that would intervene in the hegenonic practice of naming and defining, has been argued by Judith Halberstam, drawing from Eve Sedgwick $(8,46-7)$. As Halberstam goes on to note "The sexual discourse we have settied for is woefully inadequate when it comes to accounting for the myriad practices that fall beyond the purview of home and heteronormativity. The development of a new sexual vocabulary and a radical sexual discourse is happening already in transgender communities, in sezual subcultures, in chubs" (139). Similar calls for an enlarged public vocabulary can be found in Feinberg (102), Stone (297), and Condit (110).

\section{WORKS CITED}

Atherton, Tony. "A Poignant Story of Brutal Intolerance." Ottawa Citizen 1 May 1999: E5. Berlant, Lauren. The Queen of America Goes to Washington City: Fssays on Sex and Citizenship. Durham, NC: Duke UP, 1997.

Bernard, Jami. "Tragic Death of a Girl Who Lived as a Guy" Daily News 23 September 1998: 48 .

"Best Bets." Detroit News \& February 1999: C4.

Boellstorff, Leslie. "Nissen's Lawyer Says Juror Misconduct Tainted Trial." Onaha World Herald 3 December 1996: 13SF.

Boone, Wike. "A Chilling Tale of Rural Ignorance." The Gazette (Montreal) 1 May 1999: c9.

Bornstein, Kate. Gender Outlaw: On Men, Women, and the Rest of Us. New York: Routledge, 1994.

"Brandon Teena Murderer Sentenced." http://data.club.ce.cmu.edu/ julie/teenarage.hem Brandon Teena Story. Dir. By Susan Muska and Greta Olafsdottir. Zeitgeist Films, 1998.

"A Brief Rerninder of Hate." Toronto Strr 30 April 1999.

Brucker-Cohen, Jonah. "Brandon." ID Sept/Oet. 1998: 86.

Bunn, Austin. "Fanning the Fame." Village Vice 21 July 1998:33.

Burbach, Chris. "3 Judges to Decide Lotter's Fate." Omana Worla Herald 19 November 1995: $1 \mathrm{~B}$.

Burbach, Chris. "Ex-Girlfriend Testifies Lotter Threatened One Victim Earlier." Omaha World Herald 19 May 1995: 13SF.

Burbach, Chris. "Jury Chosen for Lotter Murder Trial." Omaha World Herald 11 May 2995: 15SF:

Burbach, Chris. "Jury Convicts Nissen in Slayings of 3 at Humboldt Farmhouse." Omaha World Herald 4 March 1995: 1.

Burbach, Chris. "Jury Told How Bodies Found Triply Slaying Trial Begins." Omaha World Herald 21 February 1995 : 11SF.

Burbach, Chris. "Mothers of 3 Victims First to Testify in Slaying Trial." Omahe World Herald 22 February 1995: 15SF.

Burbech, Chris. "Officer: Sheriff Delayed Falls City Suspects' Arrest." Omaha World Herald 27 October 1994: 17SF.

Burbach, Chris. "Prosecutor Sees 'Intent' in 3 Killings." Omaha World Herald 16 May 1995: 1 . 
Burbach, Chris. "Tight Security Planned for Triple-Murder Trial." Omaha World Herald 21 February 1995: 1.

Burbach, Chris and Henry 3. Cordes. "Romance, Deceit and Rage." Omaha World Herald 9 January 1994: 1A.

Butler, Judith. Bodies that Matter: On the Discursive limits of 'Sex.' New York: Routledge, 1993.

Butler, Judith. Gender Trouble: Feminiam and the Subversion of Identity. New York: Routledge, 1990.

Carr, Jay. "Denial and Death in Falls City." Boston Globe 15 January 1999: D7.

Chase, Cheryl. "Hermaphrodites with Attitude: Mapping the Emergence of Intersex Political Action." GLQ 4 (1998): 189-212.

Condit, Celeste M. "Hegemony in a Mass-mediated Society: Concordance about Reproductive Technolegies." Critical Studies in Mass Communication. 11 (1994): 205-230.

Condit, Celeste M. "In Praise of Eloquent Diversity: Gender and Rhetoric as Public Persuasion." Women's Studies in Communication. 20 (1997): 91-116.

"Crossing Over:" 20/20. ABC News 1 Aug. 1997.

"Datehine Iowa." Des Moines Register 8 May 1998: 7.

"Deception on the Prairie." Advocate 8 Feb. 1994: 16-17.

Delmont, Jim. "Murder' Vividly Portrays Shocking Triple Killings." Omaha Wortd Herald 24 May 1997: 61SF.

Dreger, Alice Domurat. Hermaphrodites and the Medical Invention of Sex. Cambridge: Harvard UP, 1998.

Dunne, John Gregory. "The Humboldt Murders." New Yorker 13 Jan. 1997: 45-62.

Elliot, Patricia and Katrina Roen. "Transgenderism and the Question of Embodiment: Promising Queer Politics?" GLQ 4 (1998): 231-262.

Eilliot, David. "A Tortured Soul Sinks into the Bleak Landscape of 'Brandon Teena Story." " San Diego Union Tribune 26 March 1998: E10.

Epstein, Julia and Kristina Straub. "Introduction: The Guarded Body." Body Guards: The Cultural Politics of Gender Ambiguity. Ed. Julia Epstein and Kristina Straub. New York: Routledge, 1991. 1-28.

Feinberg, Leslie. Transgender Warriors: Making History from Joan of Arc to Dennis Rodman. Boston: Beacon, 1996.

"Fierce Flicks." Ms. Sept/Oct. 1998: 85.

Fruhling, Larry. "Charade Revealed Prion to Kilings." The Des Moines Register 9 January 1994: 1.

Garber, Marjorie. Vested Interests: Cross-Dressing and Cultural Anxiety. Routledge: New York, 1992.

Grabrenya, Frank. "Tale of Masquerade, Murder Should Spark Conversation." Columbus Dispatch 7 January 1999: 4.

Greene, Ronald Walter. "Another Materialist Rhetoric." Critical Studies in Mass Communication 15 (1998): 21-40.

Guthman, Edward. "Brandon' Makes Simple Plea for Compassion." San Francisco Chronicle 19 February 1998: D3.

Halberstam, Judith. Female Mascuilinity. Durham: Duke University Press, 1998.

Hale, C. Jacob. "Consuming the Living, Dis(re)membering the Dead in the Butch/Ftm Borderlands." GLQ 4(1998): 311-348.

Hale, Jacob. "Suggested Rules for Non-Transsexuals Writing About Transsexuals, Transsexuality, or Trans-.". http:/www.actlab.utexas.edw/ -sandy/hale.rules.htmlrules.heml

Hammel, Paul. "Relatives Say Victim was Threatened by Two Men." Omaha World Herald 3 January 1994: 9FS.

Hartl, John. "Seattle International Film Festival." Seattle Times 7 June 1998: M1.

Holden, Stephen. "A Rape and Beating, Later 3 Murders and Then the Twist." New York Times 23 Sept. 1998: 5.

Huisman, Mark J. "Docfest." Village Voice 2 June 1998: 160.

Jones, Aphrodite. All She Wanted: A True Story of Sexual Deception and Murder in America's Heartland. New York: Pocket Books, 1996. 
Keenan, John. "Brandon Teena' a Chilling Decumentary" Omaha World-Herald 21 October 1998: 45 .

Kessler, Suzanne J. Lessons from the Intersexed. New Brunswick, NJ: Rutgers University Press, 1998.

Kessier, Suzanne J. "The Medical Construction of Gender: Case Management of Intersexed Infants." Signs: Journal of Women in Culiure and Society 16 (1990): 3-26.

Kielwasser, Alfred P. and Michelle Woif. "Mainstream Television, Adolescent Homosexuality, and Significant Silence." Critical Studies in Mass Communication 9 (1992): $350-373$.

Konigsberg, Eric. "Death of a Deceiver." Playboy Jan. 1995:92-94, $193-199$.

Laqueur, Thomas. Making Sex: Body and Gender from the Greeks to Freud. Cambridge: Harvard University Press, 1990.

Lee, Gretehen. "Homophobis in the Heartland." Curve Sept. 1998: 16-17.

McKerrow, Raymie E. "Critical Rhetoric: Theory and Prazis." Communication Monographs 56 (1989): 91-111.

MicGee, Michael Calvin. "rext, Context, and the Fragmentation of Contemporary Culture." Western Eorrnal of Speech Communication 54 (1990): 274-289.

Minge, Jim. "Film to Depict Triple Murder." Omaha World Herald 21 October 1895: 61SF.

Minkowitz, Donna. "Love Hurts." Village Voice 19 April 1994: 24-30.

Moton, Tony. "Documentary Only the First." Omaha World Herald 22 October 1998: 41.

Mhoton, Tony. "Film Tracks Murder Case." Omaha World Hercld 13 October 1996: 1E.

Moton, Tony. "Story Inspires Filmanakers." Omaha World Herald 5 November 1995: 1:.

"Murder Case Inspires New Play." Ornaha World Herald 18 May 1997: 11.

"New Trial Sought in Triple Killing." Des Moines Register 8 May 1998.

Powell, Joy. "Lawsuit Against Former Sheriff Dismissed in Humboldt Case." Omaha World Herald 11 August 1995: 18.

"Prison Term in Death of Cross-Dresser." Des Moines Register 1 September 1995: 7.

Probyn, Elspeth. Sexing the Self: Gendered Positions in Cultural Studies. New Yorix: Routledge, 1993.

Ramet, Sabrina Petra. "Gender Reversals and Gender Cultures: An Introduction." Gender Reversais and Gender Cultures: Anthropological and Historical Perspectives. Ed. Sabrina Petra Ramet. New York: Routledge, 1996. 1-21.

Ricks, Ingrid. "Heartland Homicide." The Advocate 8 March 1994:28-30.

"Gecond Trial in Killing of 3 Begins Today." Des Moines Register 15 May 1995: 2.

Shapiro, Judith. "Trenssexualism: Refiections on the Persistence of Gender and the Mutability of Sex." Body Guards: The Cultural Politics of Gender Ambiguity. Ed. Julia Epstein and Kristina Straub. New York: Routledge, 1991. 248-279.

Stone, Sandy. "The Fmpire Strikes Back: A Posttransexual Manifesto." Body Guards: The Cultural Policics of Gender Ambiguity. Ed. Julia Epstein and Kristina Straub. New York: Routledge, 1991. 280-304.

Strawbridge, Patrick. "Judge Dismisses Federal Suit in Slaying of Teena Brandon." Omaha World Herald 10 November 1998: 21.

Stryker, Susan. "The Transgender Issue: An Introduction." GLQ 4 (1998): 145-158.

Taubin, Amy. "Splitting Image." Village Voice 29 Sept. 1998: 128.

Thomas, Kevin. "Outfest '98 Saves Its Best for Last." Los Angeles Tines 18 Sept. 1998: F16.

Wade, Geraid. "Author Hopes Crime Books Can Make a Difference." Omaka World Hercld 27 May 1996: 33SF.

Wheelwright, Julie. "The Boyfriend." The Guardian 20 February 1996: T6.

Will, Ed. "Murder in a Small Town." Denver Post 6 Marck 1994: 10.

"Woman Who Posed As A Man is Found Slain with 2 Others." New York Times 4 Jan. 1994: A11.

"Zeitgeist Films: The Brandon Teena Story: The Crime." http:/www:zeitgeist.com/current/ branconteena/brandoncrime.html. 